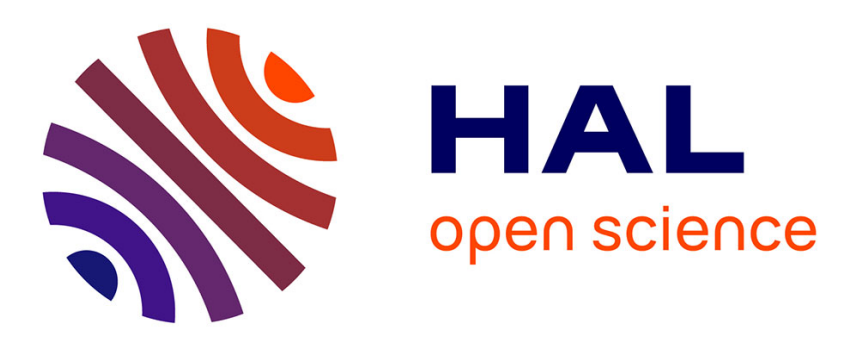

\title{
A risk assessment study on accidents at French level crossings using Bayesian belief networks \\ Ci Liang, Mohamed Ghazel
}

\section{To cite this version:}

Ci Liang, Mohamed Ghazel. A risk assessment study on accidents at French level crossings using Bayesian belief networks. International Journal of Injury Control and Safety Promotion, 2017, 15p. 10.1080/17457300.2017.1416480 . hal-01680200

\section{HAL Id: hal-01680200 https://hal.science/hal-01680200}

Submitted on 10 Jan 2018

HAL is a multi-disciplinary open access archive for the deposit and dissemination of scientific research documents, whether they are published or not. The documents may come from teaching and research institutions in France or abroad, or from public or private research centers.
L'archive ouverte pluridisciplinaire HAL, est destinée au dépôt et à la diffusion de documents scientifiques de niveau recherche, publiés ou non, émanant des établissements d'enseignement et de recherche français ou étrangers, des laboratoires publics ou privés. 


\title{
A risk assessment study on accidents at French level crossings using Bayesian belief networks
}

\author{
Ci Liang a,b,c,*, Mohamed Ghazel b,a,c \\ ${ }^{a}$ FCS Railenium, Valenciennes, France \\ ${ }^{b}$ IFSTTAR-COSYS/ESTAS, Lille-Villeneuve d'Ascq, France \\ ${ }^{c}$ University Lille 1, Lille-Villeneuve d'Ascq, France
}

\begin{abstract}
Level crossing (LX) safety continues to be one of the most critical issues for railways despite an ever-increasing focus on improving design and application practices. Accidents at European LXs account for about one-third of the entire railway accidents. They result in more than 300 deaths every year in Europe. Due to the non-deterministic causes, the complex operation background and the lack of thorough statistical analysis based on detailed accident/incident data, the risk assessment of LXs remains a challenging task. In the present paper, a general framework of Probabilistic Risk Assessment and Improvement Decision based on Bayesian Belief Networks (PRAID-BBN) is discussed. The developed framework aims to analyze various impacting factors which may cause LX accidents, and quantify the contribution of these factors so as to identify the crucial factors which contribute most to the accidents at LXs, thus allowing for providing improvement measures to reduce risk and costs related to LX accidents. A detailed statistical analysis is firstly carried out based on the accident/incident data. Then, a Bayesian belief network (BBN) risk model is established according to the statistical results. In order to validate the effectiveness of this approach, we apply the PRAID-BBN framework on the basis of the accident/incident data provided by SNCF, the French national railway operator. The main outputs of our study are conducive to efficiently focusing on the effort/budget to make LXs safer.
\end{abstract}

Keywords: level crossing safety; statistical analysis; Bayesian belief networks; risk assessment

\section{Context and related works}

\subsection{Literature review on level crossing safety study}

Accidents at railway level crossings (LXs) often give rise to serious material and human damage and seriously hamper railway safety reputation, although the majority of accidents are caused by road user violations. LX safety is one of the most critical issues in railways, which needs to be improved urgently (Ghazel, 2009; Mekki et al., 2012; Liu et al., 2016). In 2012, there were more than 118,000 LXs in the 28 countries of the European Union (E.U.) which correspond to an average of 5 LXs per 10 line-km (ERA, 2014). Accidents at European LXs account for about one-third of the entire railway accidents. They result in more than 300 deaths every year in Europe (Liu et al., 2016). In some European countries, accidents at LXs account for up to $50 \%$ of railway accidents (Ghazel \& El-Koursi, 2014; Evans, 2011b). In the entire E.U. area, the overall number of fatalities per fatal accident in railways from 1990 to 2009 is 4.10, with no apparent long-term change over time (Evans, 2011a). In France, the railway network shows more than $15,000 \mathrm{LXs}$ for $30,000 \mathrm{~km}$ of railway lines, which are crossed daily by 16 million vehicles on average, and around 13,000 LXs show heavy road and railway traffic (SNCF Réseau, 2011). In 2013, €32 million was spent by the State, SNCF (the French national railway operator) and local authorities, to improve LX safety, and about €36 million was invested in 2014. Despite numerous measures taken to improve LX safety, SNCF Réseau (the French national railway infrastructure manager) counted 100 collisions at LXs leading to 25 deaths in 2014. This was half the total number of collisions at LXs a decade ago, but still too many (SNCF Réseau, 2015). In order to significantly reduce the accidents and cost at LXs, it is necessary to develop further safety solutions to reach a more effective result.

${ }^{*}$ Corresponding author. IFSTTAR, Lille-Villeneuve d'Ascq, 20 Rue Élisée Reclus, BP 70317 F-59666 Villeneuve d'Ascq Cedex. Email: ci.liang@railenium.eu. Tel.: +33(0)320438310. 
In the literature pertaining to LX safety, a number of works can be found. In recent years, a systems analysis framework (Leveson, 2011; Read et al., 2016; Wilson, 2014) and a psychological schema theory (Salmon et al., 2013; Stanton \&Walker, 2011) have been used to analyze the contributory factors underlying the accident occurring at LXs. The study presented by Salmon et al. (2013) described a collision between a loaded semi-trailer truck and a train, occurring in North Victoria. In this study, when the truck crossed the LX, the train was approaching while the flashing lights of the LX were not triggered. According to the investigation of the Office of the Chief Investigator (OCI), the truck driver in this study was not aware of the train and the activated state of the LX until it was too late to stop. A study conducted by Davey et al. (2008) discussed the intentional violation of vehicle drivers crossing LXs, particularly focusing on vehicle driver complacency due to the high level of familiarity. Tey et al. (2011) conducted an experiment to measure vehicle driver response to LXs equipped with stop signs (passive), flashing lights and half barriers with flashing lights (active) respectively. In this study, the vehicle driver responses result from both the field survey and a driving simulator.

Based on the above investigations, the main available studies dealing with LX safety have tended to take a qualitative approach to understand the potential factors causing accidents at LXs. They employed surveys, interviews, focus group methods or driving simulators, rather than collecting real field data. As a consequence, the aforementioned approaches show some limits. For instance, the reaction of vehicle drivers in simulation scenarios could differ from that in reality, due to the different levels of feeling of danger. Although those qualitative approaches are beneficial to explore the potential factors causing accidents, they do not allow for quantifying the contribution degree of these factors. Thereby, quantitative approaches are indispensable if we want to understand the impacting factors thoroughly and enable the identification of practical design and improvement recommendations to prevent accidents at LXs. The present study falls within this scope, and aims to establish some means that allow for identifying and quantifying the contribution of the various impacting factors pertaining to LX safety.

\subsection{Literature review on risk modeling}

Nowadays, risk analysis methodologies are required to deal with increasingly complex systems with a large number of configuration parameters. Therefore, such methodologies should be equipped with the following characteristics:

- Strong modeling ability;

- Easy to specify a risk scenario or a system;

- High computational efficiency.

In the domain of risk assessment, various methodologies are adopted for the modeling and analyzing processes. Due to the combination of qualitative and quantitative analysis, the Fault Tree Analysis (FTA) developed by H.A. Watson at Bell Laboratories (Ericson \& Li, 1999) has been widely used for risk analysis in various domains. FTA is a deductive and top-down method which aims at analyzing the effects of initiating faults and events on a complex system and offering the designer an intuitive highlevel abstraction of the system. Compared with the Failure Mode and Effects Analysis (FMEA), which is an inductive and bottom-up analysis method aimed at analyzing the effects of single component or function failures on equipment or subsystems, FTA is more useful in showing how resistant a system is to single or multiple initiating faults. However, one obvious disadvantage of FTA is that it is not clear on failure mechanism, since the causal relationship between events is not a simple YES or NO (1 or 0$)$. Therefore, FTA is prone to missing the possible initiating faults. In addition, traditional static fault trees cannot handle the sequential interaction and functional dependencies between components. Consequently, it is necessary to employ dynamic methodologies to overcome these weaknesses. Markov Chains (MCs) and their extensions have been mainly used for modeling complex dynamic system behavior and dependability analysis of dynamic systems. Two-state Markov switching multinomial logit models are introduced to explain unpredictable, unidentified or unobservable risk factors in road safety by Malyshkina and Mannering (2009). Although MCs can elaborate the statistical state transition of different variables, they cannot formalize causal relationships between the various events.

Afterward, risk analysis based on formal modeling expanded. In order to compare the effectiveness of two main Automatic Protection Systems (APSs) at LXs: two-half-barrier APS and four-half-barrier 
APS, Generalized Stochastic Petri Nets (GSPNs) were used to analyze the aleatory fluctuations of various parameters involved in the dynamics within the LX area by Ghazel and El-Koursi (2014). Over the last few years, Bayesian network (BN), a method of reasoning using probabilities, has been an increasingly popular method used for risk analysis of safety-critical systems or large and complex dynamic systems (Chemweno et al., 2015). In order to obtain proper and effective risk control, risk planning should be performed based on risk causality which can provide more information for decision making. In this context, a model using BNs with causality constraints (BNCC) for risk analysis was proposed by $\mathrm{Hu}$ et al. (2013). The BN technique offers interesting features: the flexibility of modeling, strong modeling power, high computational efficiency and, most importantly, the outstanding advantage involving causality analysis of both forward inference and reverse inference (Weber et al., 2012).

Therefore, based on the above investigation of risk analysis methodologies, a general framework of Probabilistic Risk Assessment and Improvement Decision based on Bayesian Belief Networks (PRAIDBBN) is presented in this article to deal with the risk assessment at LXs. Namely, a thorough statistical analysis based on the accident/incident data pertaining to French LXs is firstly performed, and the statistical results are used as the import sources of BBN risk model. Then, the BBN risk model is developed according to the causal relationships between the accidents and various impacting parameters considered. Through the BBN risk model, one can quantify the risk level influenced by various potential factors and identify the factors which contribute most to the accidents at LXs, as well as their combined impact on LX safety.

The rest of this paper is organized as follows: in section 2, the theory of probability which underlines BBN models is recalled. In section 3, the integrated framework of PRAID-BBN is elaborated. Then, we apply the PRAID-BBN approach based on the accident/incident data provided by SNCF, in order to analyze the LX risk and the impact of various factors. In this section, a statistical analysis is performed and a risk model is established. Here, the "GeNIe" software tool is used as a BBN modeling instrument to formalize the causal relationships between the accident occurrence and the impacting parameters considered. Section 4 deals with the model validation. Namely, the assessment of model performance is carried out based on appropriate statistical means and the analytical outcomes are discussed. Finally, some concluding remarks and further directions are given in section 5.

\section{Preliminary introduction of Bayesian belief networks}

In railways, potential hazards including equipment failures, human errors and some nondeterministic factors, such as environment aspects, may lead to accidents. In fact, causalities between accidents and these impacting factors exist, as shown in Figure 1. Identifying such causality relationships is a crucial issue in the process of reasoning. In particular, a functional intelligent identification model should have the ability of making reasoning based on the causal knowledge.

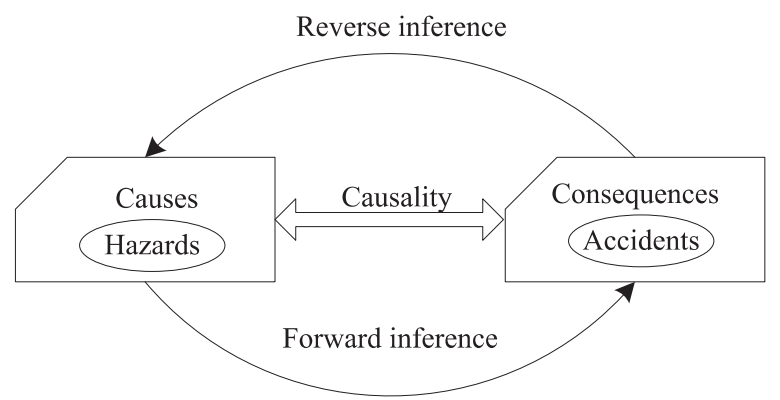

Figure 1. Reasoning between hazards and accidents.

The Bayesian belief network (BBN) employed to model causality is a graphical model that can be characterized by its structure and a set of parameters (Yehezkel \& Lerner, 2009). $B B N=(P, G)$, where $P$ represents the parameters of prior probabilities that quantify the arcs, while $G$ defines the model 
structure. $G=(V, A)$, which is a Directed Acyclic Graph (DAG), is comprised by a finite set of nodes $(V)$ linked by directed $\operatorname{arcs}(A)$. The nodes represent random variables $\left(V_{i}\right)$ and directed $\operatorname{arcs}\left(A_{i}\right)$ between pairs of nodes represent dependencies between the variables (Langseth \& Portinale, 2007).

The BBN works based on the theory of probability. Assume that there is a set of mutually exclusive events $B_{1}, B_{2}, \ldots, B_{\mathrm{n}}$ and event $A$, in addition, $P(A)$ can be expressed as follows:

$$
P(A)=\sum_{i=1}^{n} P\left(B_{i}\right) P\left(A \mid B_{i}\right)
$$

According to Bayes formula:

$$
P\left(B_{i} \mid A\right)=\frac{P\left(B_{i}\right) P\left(A \mid B_{i}\right)}{\sum_{j=1}^{n} P\left(B_{j}\right) P\left(A \mid B_{j}\right)}
$$

Eq. (2) can be converted into:

$$
P\left(B_{i} \mid A\right)=\frac{P\left(B_{i}\right) P\left(A \mid B_{i}\right)}{P(A)}
$$

$P\left(B_{i}\right)$ is the Prior Probability, $P\left(B_{i} \mid A\right)$ is the posterior (conditional) probability. When evidence of the nodes is given in a BBN, the posterior probability can be computed.

For any set of random variables in a BBN, the joint distribution can be calculated through conditional probabilities using the chain rule as shown in Eq. (4):

$$
P\left(X_{1}=x_{1}, \ldots, X_{\mathrm{n}}=x_{n}\right)=\prod_{v=1, v \in V}^{n} P\left(X_{v}=x_{v} \mid X_{v+1}=x_{v+1}, \ldots, X_{\mathrm{n}}=x_{n}\right)
$$

Due to the conditional independence, $X_{v}$ only relates to its parent nodes $P a\left(X_{v}\right)$ and is independent of other nodes. Hence, Eq. (4) can be rewritten as follows:

$$
P\left(X_{1}=x_{1}, \ldots, X_{\mathrm{n}}=x_{n}\right)=\prod_{v=1, v \in V}^{n} P\left(X_{v}=x_{v} \mid P a\left(X_{v}\right)\right)
$$

For more details about BBN, the reader can refer to a tutorial book of Bayesian networks edited by Pourret et al. (2008).

\section{LX risk assessment}

As mentioned before, the present study aims to perform risk assessment at French LXs. Therefore, the PRAID-BBN approach is illustrated to assist our risk assessment based on the accident/incident data collected by SNCF. Namely, it is applied to predicting the probability of LX accident occurrence and assessing the risk level with regard to various impacting factors taken into account. Therefore, we pave the way towards identifying the important factors which contribute most to the overall risk.

\subsection{PRAID-BBN Framework}

A modeling paradigm should view an influential network not merely as passive parsimonious codes for storing factual knowledge, but also as a computational architecture for reasoning about the knowledge involved. The PRAID-BBN is developed based on this principle, that is, the links in the network should be treated as the only pathways and activation units that direct and propel the flow of data in the process of querying and updating causal knowledge. 


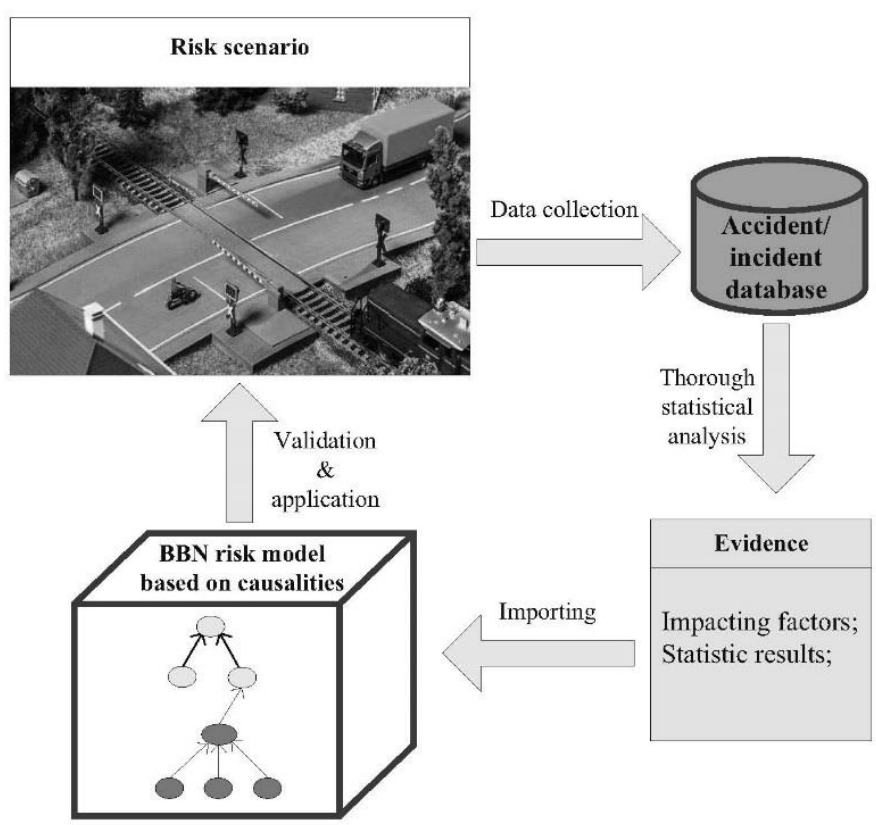

Figure 2. Framework of PRAID-BBN approach.

The PRAID-BBN framework can be illustrated as Figure 2. The process of applying PRAID-BBN approach consists of the following five stages:

1) Identifying the risk scenario that one wishes to focus on: before performing risk assessment and in order to set our research target, we must make a clear definition of the risk scenario boundary, and concentrate on this defined risk scenario to ensure that the follow-up study does not deviate from our original intention.

2) Collecting accident/incident data related to the defined risk scenario: for predicting accident probability, assessing risk level and identifying improvement measures, accident/incident data related to the defined risk scenario need to be collected. These data should be recorded in a workable database and used as the sources of the statistical analysis in step 3).

3) Performing statistical analysis on the accident/incident data: a statistical analysis on the accident/incident data aims to identify impacting factors and further explore their statistic characteristics. The outcomes of the statistical analysis shall be used as the import evidence of BBN risk model (cf. step 4)).

4) Establishing the BBN risk model based on the outcomes of statistical analysis: one builds the BBN model architecture with respect to the causal relationships between the identified impacting factors and accident/incident occurrence. For this aim, the statistical results are employed as the import evidence of the BBN risk model.

5) Predicting accident probability and assessing risk level based on the BBN risk model: on the basis of the BBN established in step 4), the risk level is quantitatively assessed, namely, by determining the occurrence probability of the investigated accident. Moreover, the impacting factors which contribute most to the investigated risky scenario are identified to provide improvement measures for reducing the risk considered and its generated cost.

\section{2. $\quad$ Risk scenario identification and data collection}

There are four LX types in France (SNCF, 2015) according to the data of SNCF:

a) SAL4: Automated LXs with four half barriers and flashing lights;

b) SAL2: Automated LXs with two half barriers and flashing lights; 
c) SAL0: Automated LXs with flashing lights but without barriers;

d) Crossbuck LXs, without automatic signaling.

As shown in Table 1, SAL2 (more than 10,000) is the most widely used type of LX in France. Moreover, in terms of accident occurrence, more than 4,000 accidents at SAL2 contributed most to the total number of accidents at French LXs from 1974 to 2014.

Table 1. Accidents at different types of LXs in France from 1974 to 2014.

\begin{tabular}{lll}
\hline Type of LX & Number & \# Accident \\
\hline SAL4 & $>600$ & $>600$ \\
SAL2 & $>10,000$ & $>4,000$ \\
SAL0 & $>60$ & $>50$ \\
Crossbuck LX & $>3,000$ & $>700$
\end{tabular}

For the aforementioned reasons, we consider "road users crossing SAL2 LXs when trains are arriving" as the risk scenario. In terms of data collection, for operation monitoring purposes, the French national railway infrastructure manager has installed detecting sensors at LXs along each railway line. These sensors detect and collect various attributes of LX accidents/incidents and surrounding characteristics of LXs. The collected data, which are the basis of the following statistical analysis, are stored in a dedicated database.

\subsection{Preliminary statistical analysis}

In this section, statistical analysis with respect to traffic moment, different kinds of transport mode and different geographical regions is performed to establish the potential causalities between these factors and accident occurrence, and characterize the involvement of these factors. The choice of these parameters is motivated by some preliminary analysis performed in past qualitative studies, and that will not be discussed here.

There are 21 geographical administrative regions in mainland France. Accidents which are caused by the following transport modes: 1) motorized vehicle (MV), 2) pedestrian and bicycle (PB), are respectively considered to make statistical analysis in different regions. The number of train-MV accidents (\# Acc_MV) and train-PB accidents (\# Acc_PB) and the number of SAL2 LXs (\# SAL2) in 21 regions are shown in Figure 3. One can notice that train-MV accidents are much more than train-PB accidents at SAL2 LXs in each region. Further analysis related to train-MV accident frequency and train-PB accident frequency is presented in the following content.

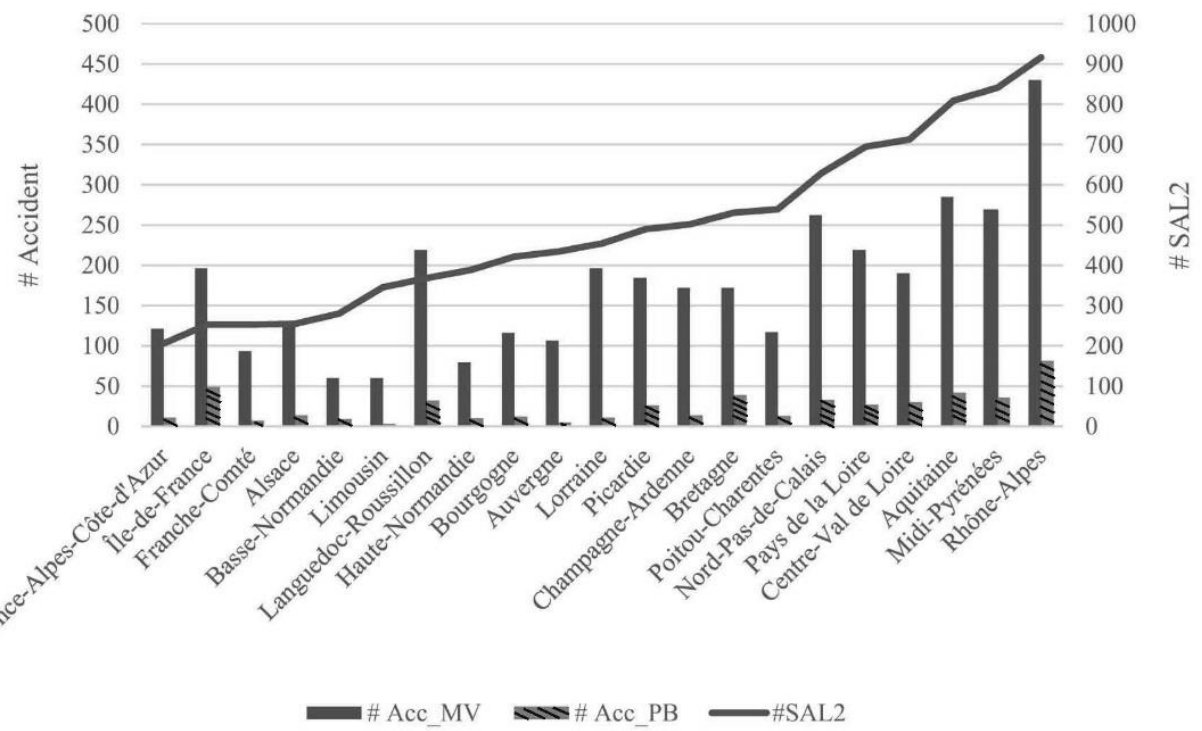

Figure 3. Accidents caused by different transport modes at SAL2 LXs in 21 French regions from 1974 to 2013. 


\subsubsection{General accident frequency analysis}

The general accident frequency of accidents occurring at each SAL2 per year is used to reflect the general risk level involving total accidents, train-MV accidents and train-PB accidents in different regions during the 40 years from 1974 to 2013 . We can calculate the general accident frequency as shown in Eq. (6):

$$
F_{G_{i}}=\frac{N b_{-} a c c_{i}}{N b_{-} S A L 2_{i} \times N b_{-} \text {year }}, i=1,2, \ldots, 21
$$

where $F_{G_{\mathrm{i}}}$ represents the general frequency in $i^{\text {th }}$ region; $N b \_a c c_{i}$ is the number of accidents occurring in $i^{\text {th }}$ region, $N b \_S A L 2_{i}$ is the number of SAL2 in $i^{\text {th }}$ region, and $N b \_y e a r$ is duration, in years, of the period considered. Three kinds of general frequency related to total accidents, train-MV accidents, and train-PB accidents will be computed. Correspondingly, the numbers of total accidents, train-MV accidents, and train-PB accidents are presented as $N b_{-} a c c_{i}$ respectively when calculating these three kinds of general frequency.

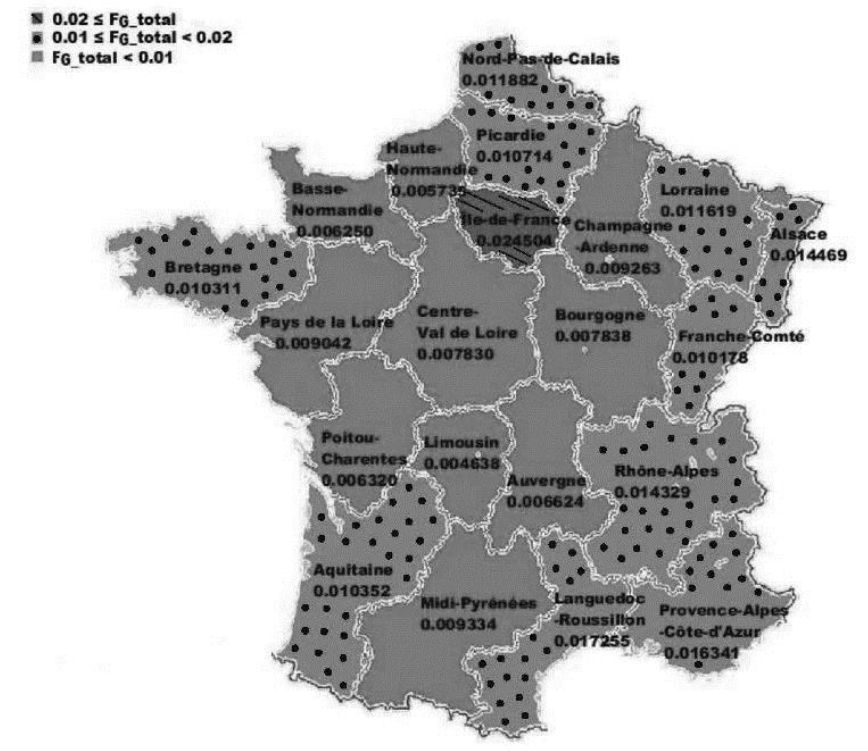

(a)

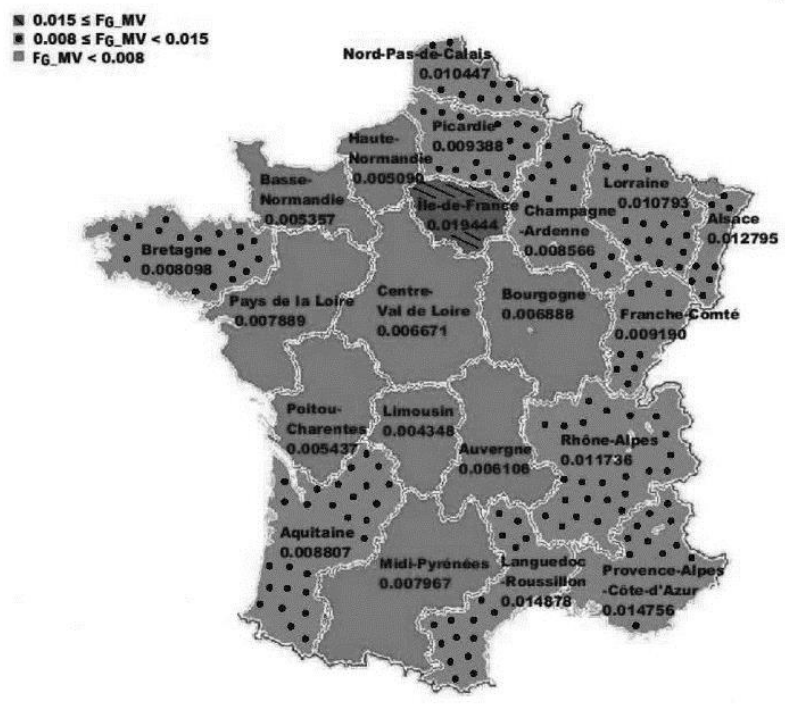

(b)

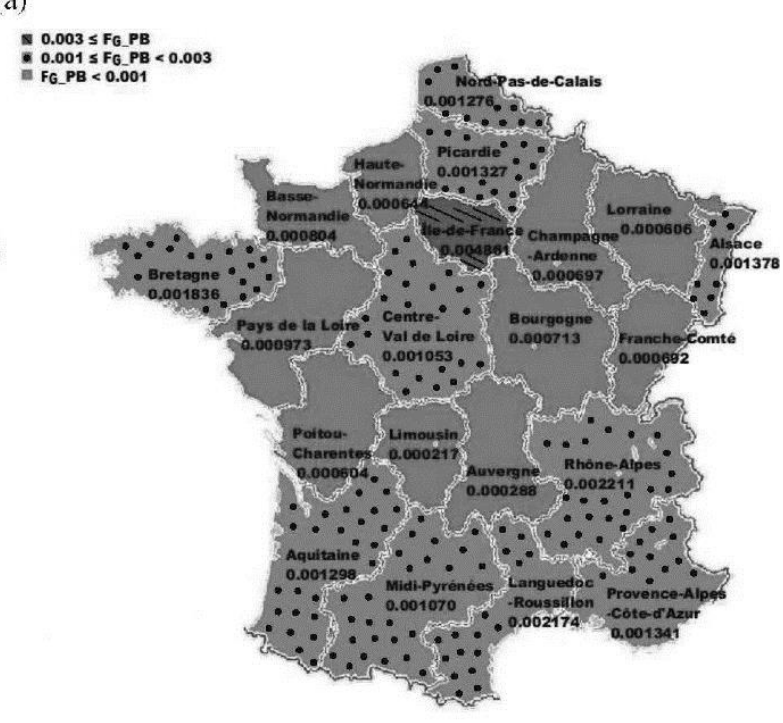

(c)

Figure 4. (a) Frequency of total accidents distributed in different regions; (b) Frequency of train-MV accident distributed in different regions; (c) Frequency of train-PB accidents distributed in different regions. 
Now that these three kinds of general accident frequency in each region are determined, maps of French regions with the general accident frequency presented are generated to show the general accident frequency distribution in different regions. As shown in Figure 4a, the general accident frequency of total accidents in the slash-filled region is the highest (greater than 0.02). The general accident frequency of total accidents in the point-filled region is the second highest (between 0.02 and 0.01), and the general accident frequency of total accidents in the blank region is the lowest (less than 0.01). When we analyze the frequency figures in detail, we find that the risk is most serious in Île-de-France (Paris and suburbs) with a general accident frequency of more than 0.02; the risk in Languedoc-Roussillon takes the second place with a general accident frequency of about 0.017 followed by the risk in Provence-Alpes-Côted'Azur with a general accident frequency of about 0.016 . On the other hand, Limousin has the lowest risk with a general accident frequency of about 0.005 . Haute-Normandie and Basse-Normandie occupy the second and the third places of lowest risk successively. Turning to Figure 3 , the number of accidents occurring in Île-de-France is not the most, but when considering the corresponding small number of SAL2 LXs, it leads to the most serious risk. As we know, Paris is located in Île-de-France. In the city of Paris there are 6 main railway stations, of which the north railway station "Gare du Nord" is one of the most frequented railway stations in the world and connects several major cities in Europe. Conversely, although accidents in Rhône-Alpes are the most with the total number of 521, the risk level is not the highest due to a large number of SAL2 LXs in this region. Limousin, HauteNormandie and Basse-Normandie have significantly fewer accidents than any other region (fewer than 100 in 40 years). That is why they have the lowest risk.

In Figures $4 \mathrm{~b}$ and $4 \mathrm{c}$, the general accident frequencies of train-MV accidents and train-PB accidents in different regions are depicted respectively. Considering train-MV accidents, the distribution of accident frequency in different regions in Figure $4 \mathrm{~b}$ is relatively consistent with the distribution of accident frequency shown in Figure 4a. However, in Figure 4c, as for train-PB accidents, the distribution of accident frequency in different regions is quite different from the distribution of total accident frequency shown in Figure 4a. Therefore, we conclude that the main transport mode causing accidents at SAL2 LXs is the motorized vehicle.

\subsubsection{Accident frequency prediction}

As mentioned in section 3.3.1, MV is the main transport mode causing accidents at SAL2 LXs. Moreover, the accidents at LXs are above all road accidents and they highly depend on the road safety level. Indeed, the correlation between the annual road accidents throughout France and annual French LX accidents is noteworthy. In this section, we will limit the scope of our analysis to train-MV accidents occurring at SAL2; in fact, from the aforementioned observation, these accidents can be considered as the most representative accidents at LXs in general. In the sequel, we will investigate the impact of the annual number of road accidents and the traffic moment on the frequency of train-MV accidents occurring at SAL2 LXs. The traffic moment gives the combined traffic frequency of railway and roadway (trains/MVs) at the LX, which is defined as follows:

\section{Traffic moment $=$ road traffic frequency $\times$ railway traffic frequency}

Therefore, for predicting the annual accident frequency at a given SAL2, we considered three parameters which are the average daily railway traffic frequency, the average daily road traffic frequency and the annual number of road accidents. Based on the accident/incident data recorded in a period of 10 years from 2004 to 2013, the prediction model is developed as follows:

$$
\lambda_{10 P}=K \times F_{R A c c} \times V^{\alpha} \times T^{\beta}
$$

where $\lambda_{10 P}$ represents the annual accident frequency at a given SAL2 during the 10 years; $F_{R A c c}$ represents the road accident factor given as: $F_{R A c c}=$ Annual road accidents in a certain year / Average road accidents over 10 years; $V$ is the average daily road traffic and $T$ is the average daily railway traffic. Here, $F_{R A c c}$ is a time-dependent variable which can reflect the variation of annual road accidents as time advances, in turn, reflects the variation of annual SAL2 accident frequency as time advances.

The nominal formula reflecting the traffic moment is the one given in Eq. (7). However, based on some previous analysis, we adopted a variant that we call "corrected moment", or CM for short. $C M=$ 
$V^{\alpha} \times T^{\beta}$, where $\beta=1-\alpha$ and the best value of $\alpha$ in terms of fitting is found to be $\alpha=0.354$ based on the previous statistical analysis performed by SNCF Réseau (SNCF Réseau, 2010). Therefore, we considered $\left(V^{0.354} \times T^{0.646}\right)$ as an integrated parameter that reflects the combined exposure frequency of both railway and road traffic. One can notice that Eq. (8) can be rewritten as $\lambda_{10 P}=K \times R M$, where $R M$ $=F_{R A c c} \times V^{0.354} \times T^{0.646}$. Thus, this model can be regarded as a linear model pertaining to annual accident frequency prediction. The Ordinary Least-Squares (OLS) method is employed to estimate the coefficient $K$. As shown in Figure 5, the coefficient $K$ is estimated as $1.319 \mathrm{e}-04$ (t-statistic $=33.72$ > 1.96 corresponding to a $95 \%$ confidence level) with the goodness of fit (GOF) $R^{2}=0.9191$. The significant impact of "corrected moment" on SAL2 accidents will be considered in the BBN risk model.

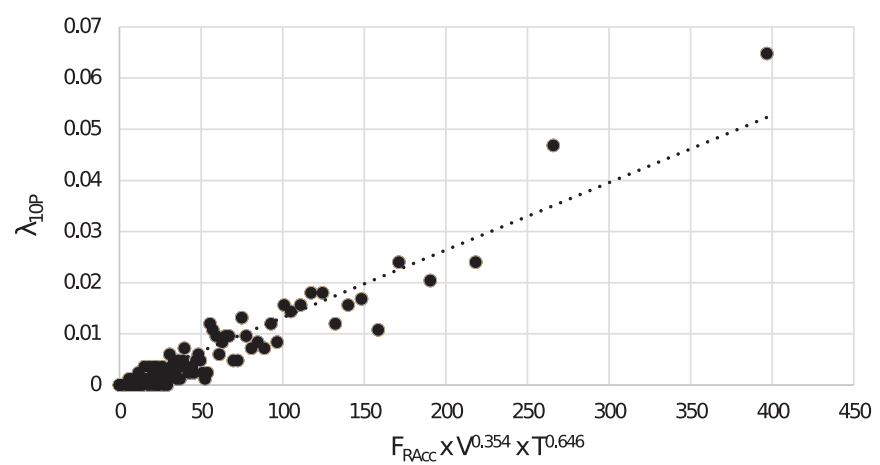

Figure 5. The accident frequency prediction model $\lambda_{10 P}$ Vs. $\left(F_{R A c c} \times V^{0.354} \times T^{0.646}\right)$.

\section{4. $\quad$ Risk model establishment}

\subsubsection{Import sources}

Based on the statistical analysis of the impact on SAL2 accident occurrence of transport mode, geographical region and corrected moment, we organized these statistical results as evidence sources which are imported to the BBN risk model. Moreover, we further considered the impact on SAL2 accident occurrence of railway speed limit. The consequence severity of SAL2 accidents (EN 50126, 1999) is defined according to the number of fatalities and injuries in an SAL2 accident. Then, monetary risk caused by fatalities and injuries can be assessed with regard to the combination of both the probability of LX accident occurrence and the corresponding consequence severity.

According to the report on cost benefit analysis for European LXs (Woods et al., 2008), the average unit costs per fatality, severe injury and minor injury in France in the past 15 years are given in Table 2. The definition of consequence severity pertaining to an accident is shown in Table 3 . Five levels of consequence severity are set according to the number of fatalities, and the severity of injuries caused by the accident, respectively. The consequence severity increases progressively from level 1 to 5 . Costs pertaining to each consequence severity level are computed according to the maximum fatalities and injuries of the given consequence severity level. The materials in Tables 2 and 3 form the basis of our monetary risk computation.

Table 2. Average unit costs per fatality, severe injury and minor injury in France in the past 15 years.

\begin{tabular}{lll}
\hline $\begin{array}{l}\text { Unit costs per fatality } \\
(\text { million } €)\end{array}$ & $\begin{array}{l}\text { Unit costs per severe injury } \\
(\text { million } €)\end{array}$ & $\begin{array}{l}\text { Unit costs per minor injury } \\
(\text { million } €)\end{array}$ \\
\hline 1.6170 & 0.2258 & 0.0170 \\
\hline
\end{tabular}

\subsubsection{Risk model establishment}

As mentioned in 3.3.1, the main transport mode causing accidents at SAL2 is the motorized vehicle. Here, we focus on the BBN model of SAL2 LX risk caused by train-MV accidents. As shown in Figure 7 , the BBN risk model is established based on the aforementioned materials and the causalities between impacting factors and train-MV accidents at SAL2 LXs, to assess the risk level related to geographical region, corrected moment $\left(V^{0.354} \times T^{0.646}\right)$ and railway speed limit. "GeNIe" is used as the BBN modeling and analysis tool. Table 4 offers a summary of states in each node of the BBN risk model. We 
determined three groups of corrected moment that contain all the SAL2 LXs such that the number of SAL2 LXs in each group is almost equal. The definition of three groups of railway speed limit is also similarly obtained.

Table 3. Consequence severity definition.

\begin{tabular}{|c|c|c|c|c|c|}
\hline Consequence severity & Level 1 & Level 2 & Level 3 & Level 4 & Level 5 \\
\hline 0 fatality, 0 severe injury, $0 \leq$ minor injuries $\leq 20$; & $x$ & - & - & - & - \\
\hline 0 fatality, 0 severe injury, $20<$ minor injuries; & $x$ & - & - & - & - \\
\hline $\begin{array}{l}0 \text { fatality, } 0<\text { severe injuries } \leq 5,0 \leq \text { minor } \\
\text { injuries } \leq 20 \text {; }\end{array}$ & - & $x$ & - & - & - \\
\hline $\begin{array}{l}0 \text { fatality, } 0<\text { severe injuries } \leq 5,20<\text { minor } \\
\text { injuries; }\end{array}$ & - & $x$ & - & - & - \\
\hline $\begin{array}{l}0 \text { fatality, } 5<\text { severe injuries, } 0 \leq \text { minor injuries } \leq \\
20 \text {; }\end{array}$ & - & - & $x$ & - & - \\
\hline 0 fatality, $5<$ severe injuries, $20<$ minor injuries; & - & - & $x$ & - & - \\
\hline $\begin{array}{l}0<\text { fatalities } \leq 5,0 \text { severe injury, } 0 \leq \text { minor } \\
\text { injuries } \leq 20\end{array}$ & - & - & $x$ & - & - \\
\hline $\begin{array}{l}0<\text { fatalities } \leq 5,0 \text { severe injury, } 20<\text { minor } \\
\text { injuries; }\end{array}$ & - & - & $x$ & - & - \\
\hline $\begin{array}{l}0<\text { fatalities } \leq 5,0<\text { severe injuries } \leq 5,0 \leq \\
\text { minor injuries } \leq 20\end{array}$ & - & - & - & $x$ & - \\
\hline $\begin{array}{l}0<\text { fatalities } \leq 5,0<\text { severe injuries } \leq 5,20< \\
\text { minor injuries; }\end{array}$ & - & - & - & $x$ & - \\
\hline $\begin{array}{l}0<\text { fatalities } \leq 5,5<\text { severe injuries, } 0 \leq \text { minor } \\
\text { injuries } \leq 20\end{array}$ & - & - & - & $x$ & - \\
\hline $\begin{array}{l}0<\text { fatalities } \leq 5,5<\text { severe injuries, } 20<\text { minor } \\
\text { injuries; }\end{array}$ & - & - & - & $x$ & - \\
\hline $\begin{array}{l}5<\text { fatalities, } 0 \leq \text { severe injuries } \leq 5,0 \leq \text { minor } \\
\text { injuries } \leq 20\end{array}$ & - & - & - & - & $x$ \\
\hline $\begin{array}{l}5<\text { fatalities, } 0 \leq \text { severe injuries } \leq 5,20<\text { minor } \\
\text { injuries; }\end{array}$ & - & - & - & - & $x$ \\
\hline $\begin{array}{l}5<\text { fatalities, } 5<\text { severe injuries, } 0 \leq \text { minor injuries } \\
\leq 20\end{array}$ & - & - & - & - & $x$ \\
\hline $\begin{array}{l}5<\text { fatalities, } 5<\text { severe injuries, } 20<\text { minor } \\
\text { injuries; }\end{array}$ & - & - & - & - & $x$ \\
\hline Cost $($ million $€)$ & 0.6630 & 1.7920 & 5.1790 & 13.2640 & 35.9020 \\
\hline
\end{tabular}

Table 4. States of nodes in the BBN risk model.

\begin{tabular}{|c|c|c|}
\hline Node name & Node property & Node State \\
\hline Region & Chance node & $\begin{array}{l}\text { Île_de_France 1, Languedoc_Roussillon 2, Provence_Alpes } \\
\text { 3, Alsace 4, Rhone_Alpes 5, Lorraine 6, } \\
\text { Nord_Pas_de_Calais 7, Picardie } 8 \text {, Franche_Comte 9, } \\
\text { Aquitaine 10, Champagne_Ardenne 11, Bretagne 12, } \\
\text { Midi_Pyrenees 13, Pays_de_la_Loire 14, Bourgogne 15, } \\
\text { Centre_Val_de_Loire 16, Auvergne 17, Poitou_Charentes } \\
\text { 18, Basse_Normandie 19, Haute_Normandie 20, Limousin } \\
\text { 21; }\end{array}$ \\
\hline Corrected Moment & Chance node & $\begin{array}{l}\text { CM_25_66 }(25 \leq \text { corrected moment }<66) \\
\text { CM_66_940 }(66 \leq \text { corrected moment } \leq 940)\end{array}$ \\
\hline Railway Speed Limit (RLS) & Chance node & $\begin{array}{l}\text { RLS_0_65 }(0 \mathrm{~km} / \mathrm{h} \leq \mathrm{RLS}<65 \mathrm{~km} / \mathrm{h}), \mathrm{RLS} 665 \_110(65 \\
\mathrm{km} / \mathrm{h} \leq \mathrm{RLS}<110 \mathrm{~km} / \mathrm{h}), \mathrm{RLS} \_110 \_220(110 \mathrm{~km} / \mathrm{h} \leq \mathrm{RLS} \\
\leq 220 \mathrm{~km} / \mathrm{h}) ;\end{array}$ \\
\hline Fatalities $(\mathrm{F})$ & Chance node & F_0 $(F=0), F \_0 \_5(0<F \leq 5), F \_5(5<F)$ \\
\hline Severe Injuries (S) & Chance node & $\mathrm{S} \_0(\mathrm{~S}=0), \mathrm{S} \_0 \_5(0<\mathrm{S} \leq 5), \mathrm{S} \_5(5<\mathrm{S})$; \\
\hline Minor Injuries (M) & Chance node & M_0_20 $(0 \leq \mathrm{M} \leq 20)$, M $\_20(20<\mathrm{M})$ \\
\hline SAL2 MV Accident & Chance node & True, False; \\
\hline
\end{tabular}




\section{Validation of prediction performance and result discussion}

\subsection{Validation process}

We adopt the Receiver Operating Characteristic (ROC) Curve and the Area under the Curve (AUC) (Hanley \& McNeil, 1982) to evaluate the prediction performance of the present BBN risk model. The ROC curve is commonly used to illustrate the performance of a binary classifier system. This curve is a two-dimensional graph that is created by plotting the true positive rate (TPR) (Y-axis) against the false positive rate (FPR) (X-axis) at various threshold settings (Powers, 2011). The TPR is known as the sensitivity, the recall or the probability of detection in machine learning. The FPR is known as the fall-out or the probability of false alarm. The ROC curve thus depicts relative trade-offs between benefits (true positives) and costs (false positives). In order to facilitate the evaluation of classifier performance, we may want to reduce ROC performance to a single scalar value that can represent the expected performance. A common method is to calculate the AUC which is a portion of the area of a unit square, and its value will always be between 0 and 1 . When using normalized units, the AUC is equal to the probability that a classifier will rank a randomly chosen positive instance higher than a randomly chosen negative one. The ROC curve of a finite set of samples is based on a step function, and its AUC can be computed by the normalized Wilcoxon-Mann-Whitney (WMW) statistic (Mozer, 2003):

$$
A U C=\frac{\sum_{i=1}^{m} \sum_{j=1}^{n} I\left(x_{i}, y_{j}\right)}{m \times n}
$$

where $x_{i}, i=1, \ldots, m$, is the sample of positive classifier outputs; $y_{j}, j=1, \ldots, n$, is the sample of negative classifier outputs and

$$
I\left(x_{i}, y_{j}\right)=\left\{\begin{array}{l}
1, x_{i}>y_{j} \\
0, \text { otherwise }
\end{array}\right.
$$

is based on pairwise comparisons between $x_{i}$ and $y_{j}$ s.

For a prediction model:

1) if $\mathrm{AUC}=1$, it is a perfect prediction model. When using it, a perfect prediction can be obtained with at least one threshold value. Generally, there is no perfect prediction model in reality.

2 ) if $0.5<\mathrm{AUC}<1$, it is better than random guessing and has relatively sound predictive value.

3 ) if $\mathrm{AUC}=0.5$, it is the same as random guessing, for example, throwing coin, which means, actually, this model has no predictive value.

4) else, AUC < 0.5, it is worse than random guessing and valueless; but obviously, for the reverseprediction, it is better than random guessing.

Therefore, the ideal perfect ROC curve is a point $(0,1)$. The closer the AUC to 1 , the better the prediction performance of a prediction model.

In our study, K-fold cross-validation method is used to perform validation process (GM, 2017). The "SAL2 MV Accident" chance node is set as the targeted node in K-fold cross-validation process since we care about the prediction accuracy of "SAL2 MV Accident" (the deterministic node and value node should be excluded when performing validation process). Here, we set $\mathrm{K}=2$, namely, the data set is divided into two parts of equal size and the first part is used for parameter training and prediction, while the second part is used for validation.

Figure 6 shows the ROC curves for "SAL2 MV Accident" chance node. The dash diagonal line indicates a baseline ROC curve for a predictor that is valuable when its real ROC curve is above this line. One can notice that two ROC curves respectively for "SAL2 MV Accident = True" and "SAL2 MV Accident = False" are both above the baseline (Global accuracy of "SAL2 MV Accident" = 0.957873 , obtained through K-fold cross-validation). Moreover, the AUC values respectively for "SAL2 MV Accident = True" and "SAL2 MV Accident $=$ False" are about $0.74(>0.5)$. 


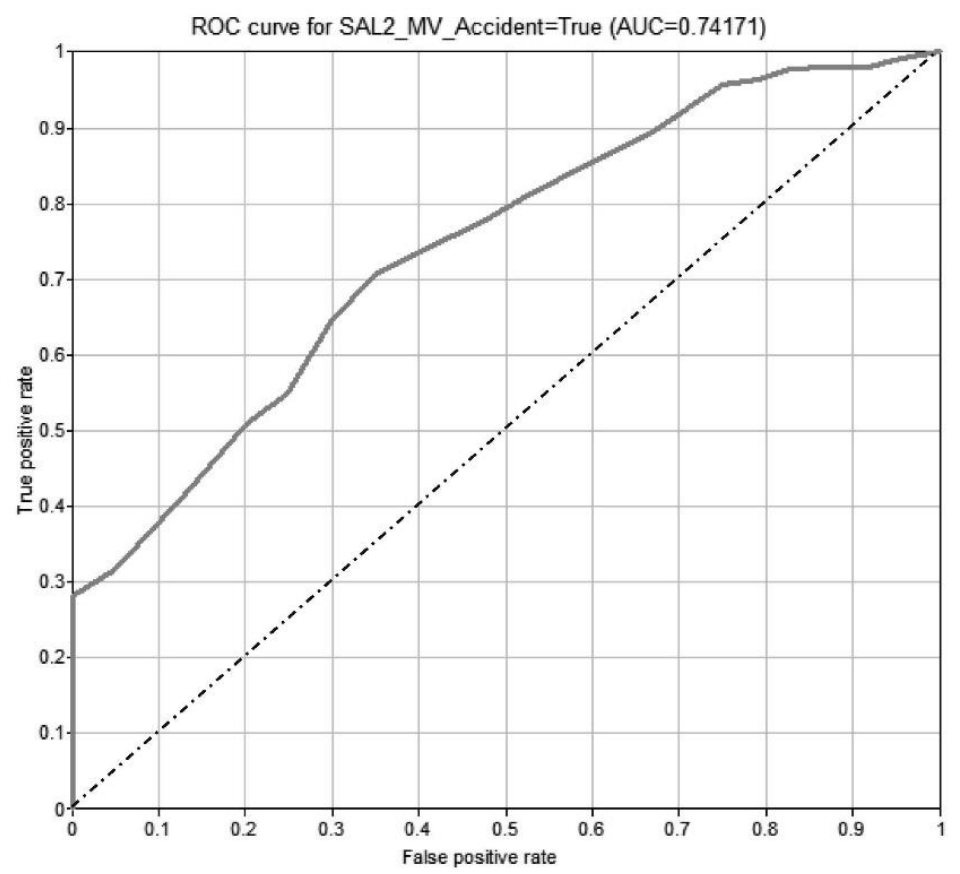

(a) ROC curve for "SAL2 MV Accident = True".

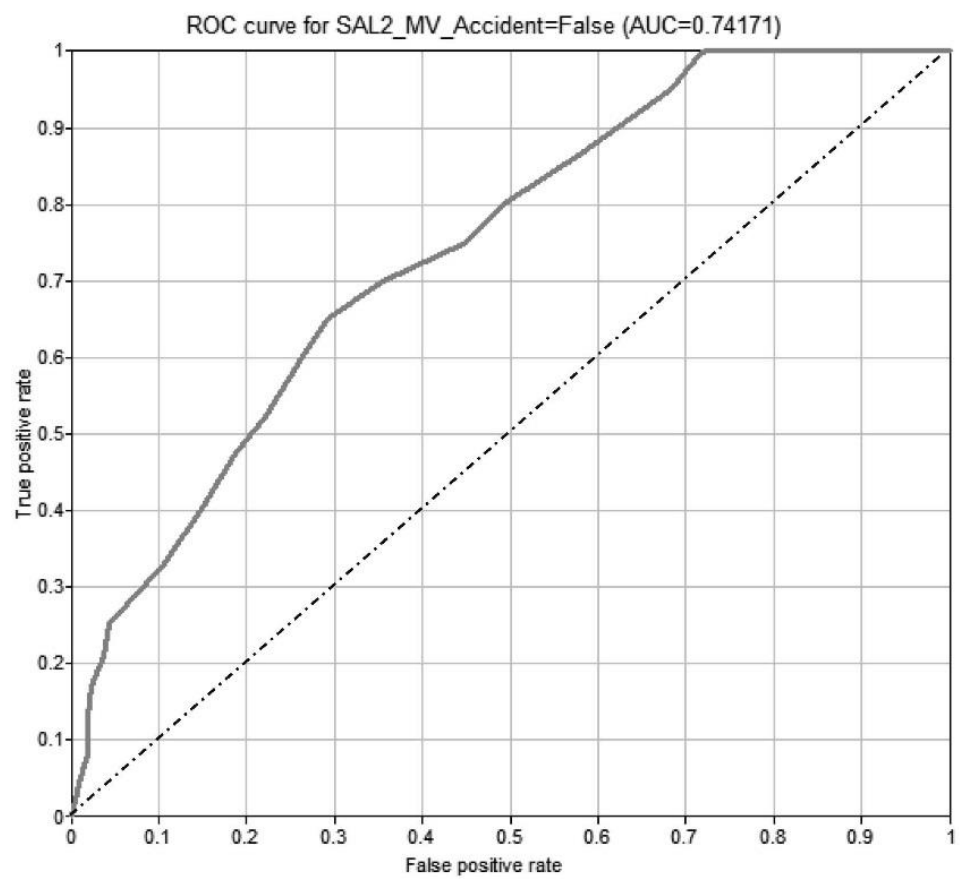

(b) ROC curve for "SAL2 MV Accident = False".

Figure 6. ROC curves for "SAL2 MV Accident" chance node.

These validation results indicate that the present BBN risk model has relatively sound prediction performance and allow us to consider the outcomes of the BBN risk model to be trustworthy.

\subsection{Discussion}

One can estimate the probability of a train-MV accident occurrence through forward inference based on the BBN risk model. The estimated general probability of a train-MV accident influenced by the interaction of geographical region, corrected moment and railway speed limit, is 0.0491. Moreover, it can be noticed that, if a given SAL2 has a large corrected moment in the "CM_66 940" group and involves high railway speed limit in the "RSL_110_220" group, the probability of a train-MV accident 
occurring at this SAL2 would increase to 0.0808. Subsequently, the "SAL2 MV Accident $=$ True" state is configured as the targeted state. In this way, one can assess the contribution degree of each factor to train-MV accident occurrence through reverse inference. Detailed results are given in Figure 7. It is worth noticing that, in terms of geographical region, there is a probability of $11 \%$ for a train-MV accident occurring in Île-de-France, which takes the first place. Moreover, the contribution degree of 21 regions to the SAL2 accident occurring is consistent with the accident frequency distribution shown in Figure 4b. In terms of corrected moment, SAL2 LXs in the largest corrected moment group "CM_66_940" have the highest risk level due to the contribution of 52\% to the train-MV accident occurring. SAL2 LXs in the smallest corrected moment group "CM_0_25" have the lowest risk level for contributing only $8 \%$ to the train-MV accident occurring. These results are consistent with the predicted trend of the SAL2 accident frequency presented by the model $\lambda_{10 P}$, that is, the higher the combined exposure of railway traffic and roadway traffic, the higher the likelihood of an SAL2 accident occurring. In terms of railway speed limit, SAL2 LXs in the highest railway speed limit group "RSL 110220 " have the highest risk level due to the contribution of $46 \%$ to the train-MV accident occurring. SAL2 LXs in the lowest railway speed limit group "RSL_0_65" have the lowest risk level for contributing $22 \%$ to the train-MV accident occurring. Generally, a high railway speed limit corresponds to a high actual train speed. Therefore, the risk for train-MV collisions is higher, since a train running with a high speed is unlikely to brake to stop prior to the LX in the case where an obstacle is detected in the intersection zone.

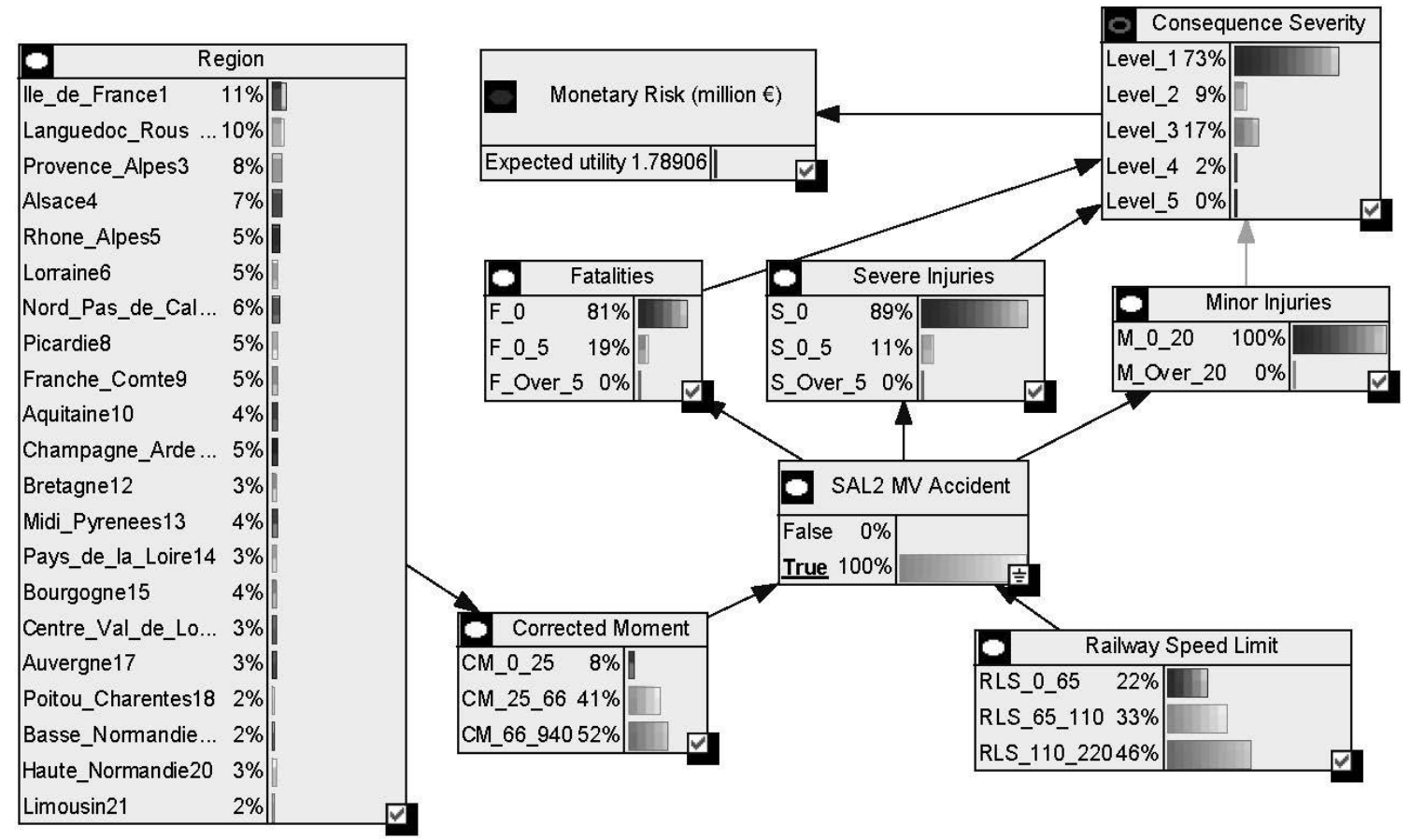

Figure 7. BBN risk model of SAL2 accident caused by motorized vehicles.

Further discussion on the consequence of accidents occurring is taken based on the BBN risk model. As shown in Figure 7, in case of a train-MV accident occurring, the probability of "not over 5 fatalities" is almost $100 \%$, in which there is a probability of about $81 \%$ for 0 fatality and a probability of about $19 \%$ for fatalities between 1 and 5 . The probability of "not over 5 severe injuries" is also about 100\%, in which there is a probability of about $89 \%$ for 0 injury and a probability of about $11 \%$ for injuries between 1 and 5. The probability of "not over 20 minor injuries" approximates $100 \%$. This means a train-MV accident hardly leads to over 5 fatalities or over 5 severe injuries, and takes a probability higher than $80 \%$ for not causing fatalities or severe injuries. Furthermore, the possible fatalities or injuries are most likely to lead to the consequence severity of level 1 as defined in Table 3, with a probability of $73 \%$, followed by the consequence severity of level 3 with a probability of $17 \%$. They hardly lead to the consequence severity of level 4 or 5. Finally, these possible fatalities or injuries involving a train-MV accident would cause a loss of about $€ 1.8$ million. Based on the aforementioned 
risk analysis results, more efforts on design improvement shall be carried out at SAL2 LXs in Île-deFrance with large corrected moment and involving high railway speed limit over $110 \mathrm{~km} / \mathrm{h}$, to reduce the overall LX risk and corresponding costs caused by accidents.

\section{Conclusion}

The contributions of the present study are as follows: an integrated risk assessment approach called PRAID-BBN is discussed. In the framework of PRAID-BBN, the risk scenario is firstly identified. Then, thorough statistical analysis is performed based on the accident/incident data pertaining to the scrutinized risk scenario. Later on, a BBN risk model is established based on the statistical analysis to quantify the occurrence probability of the risk scenario and the contribution degree of various impacting factors. Finally, a validation step is carried out on this model.

The application of PRAID-BBN to investigating French LX safety allows us to identify the main LX risk factors and quantify their respective contributions to the overall LX risk. Thanks to the PRAIDBBN approach, various significant factors pertaining to LX safety, namely, the involved road transport mode, the geographical region, the corrected moment and the railway speed limit, have been analyzed meticulously. More specifically, the statistical analysis on general frequency of the entire LX accidents, train-MV LX accidents and train-PB LX accidents in different French regions is performed. Then, a preliminary accident frequency prediction model is developed, which indicates the significant impact on train-MV LX accident occurrence of two factors: the road accident frequency and the corrected moment given by the combination of railway traffic frequency and roadway traffic frequency. Afterwards, the BBN risk model is established to assess the consequence severity and the monetary risk influenced by the aforementioned factors. The most significant contributors to the overall risk at LXs are identified through the BBN risk model. The outputs of BBN risk model can provide interesting pointers to improve safety at LXs.

It is worth noticing that the PRAID-BBN is a general framework which can be applied on various risk assessment studies. In future works, the first version of our Bayesian risk model will be enriched while integrating further factors according to the data of some experiments we are carrying out on several LXs.

\section{Acknowledgements}

This work has been in the framework of "MORIPAN project: MOdèle de RIsque pour les PAssages à Niveau" within the Railenium technological research institute, in cooperation with the National Society of French Railway Networks (SNCF Réseau) and the French Institute of Science and Technology for Transport, Development and Networks (IFSTTAR).

\section{References}

Chemweno, P., Pintelon, L., Van Horenbeek, A. \& Muchiri, P. (2015). Development of a risk assessment selection methodology for asset maintenance decision making: An analytic network process (ANP) approach. International Journal of Production Economics, 170, 663-676.

Davey, J., Wallace, A., Stenson, N. \& Freeman, J. (2008). The experiences and perceptions of heavy vehicle drivers and train drivers of dangers at railway level crossings. Accident Analysis \& Prevention, 40(3), 1217-1222.

EN 50126 (1999): Railway applications-The specification and demonstration of Reliability, Availability, Maintainability and Safety (RAMS), British Standards Institution.

Ericson, C.A. \& Li, C. (1999). Fault Tree Analysis. Proc. 17th International Systems Safety Conference. Orlando, Florida, 19.

European Railway Agency (ERA) (2014). Railway safety performance in the European Union. 9(2) Agency Regulation, $881 / 2004 / \mathrm{EC}$

Evans, A.W. (2011). Fatal accidents at railway level crossings in Great Britain 1946-2009. Accident Analysis \& Prevention, 43(5), 1837-1845.

Evans, A.W. (2011). Fatal train accidents on Europe's railways: 1980-2009. Accident Analysis \& Prevention, 43(1), $391-401$.

Ghazel, M. (2009). Using stochastic Petri nets for level-crossing collision risk assessment. IEEE Trans. on Intelligent Transportation Systems, 10(4), 668-677.

Ghazel, M. \& El-Koursi, E.-M. (2014). Two-half-barrier level crossings versus four-half-barrier level crossings: a comparative risk analysis study. IEEE Trans. on Intelligent Transportation Systems, 15(3), 1123-1133.

GeNIe manual, version 2.1.1. (2017). From http://support.bayesfusion.com/docs/ 
Hanley, J.A., McNeil, B.J. (1982). The meaning and use of the area under a receiver operating characteristic (ROC) curve. Radiology, 143(1), 29-36.

Hu, Y., Zhang, X., Ngai, E.W.T., Cai, R. \& Liu, M. (2013). Software project risk analysis using Bayesian networks with causality constraints. Decision Support Systems, 56, 439-449.

Langseth, H. \& Portinale, L. (2007). Bayesian networks in reliability. Reliab. Eng. Syst. Saf, 92, 92-108.

Larue, G.S., Rakotonirainy, A., Haworth, N.L. \& Darvell, M. (2015). Assessing driver acceptance of Intelligent Transport Systems in the context of railway level crossings. Transportation Research Part F: Traffic Psychology and Behaviour, 30, $1-13$.

Leveson, N.G. (2011). Engineering a Safer World: Systems Thinking Applied to Safety. MIT Press, Cambridge.

Liu, B., Ghazel, M. \& Toguyeni, A. (2016). Model-Based Diagnosis of Multi-Track Level Crossing Plants. IEEE Trans. on Intelligent Transportation Systems, 17(2), 546-556.

Malyshkina, N.V. \& Mannering, F.L. (2009). Markov switching multinomial logic model: an application to accident-injury severities. Accident Analysis \& Prevention, 41(4), 829-838.

Mekki, A., Ghazel, M. \& Toguyeni, A. (2012). Validation of a new functional design of automatic protection systems at level crossings with model-checking techniques. IEEE Trans. on Intelligent Transportation Systems, 13(2), 714-723.

Mozer, M.C. (2003). Optimizing classifier performance via an approximation to the Wilcoxon-Mann-Whitney statistic. In Proceedings of the $19^{\text {th }}$ International Conference on Machine Learning, 848-855.

Pourret, O., Naim, P. \& Marcot, B. (2008). Bayesian networks: a practical guide to applications. John Wiley \& Sons.

Powers, D. M. (2011). Evaluation: from precision, recall and F-measure to ROC, informedness, markedness and correlation. Journal of Machine Learning Technologies, 2(1), 37-63.

Read, G.J., Salmon, P.M., Lenné, M.G. \& Stanton, N.A. (2016). Walking the line: Understanding pedestrian behaviour and risk at rail level crossings with cognitive work analysis. Applied ergonomics, 53, 209-227.

Salmon, P.M., Read, G.J., Stanton, N.A. \& Lenné, M.G. (2013). The crash at Kerang: Investigating systemic and psychological factors leading to unintentional non-compliance at rail level crossings. Accident Analysis \& Prevention, 50, 1278-1288.

SNCF Réseau (2011). Journée Mondiale de Sécurité Routière aux Passages à Niveau [World Conference of Road Safety at Level Crossings]. From http://www.planetoscope.com/automobile/1271-nombre-de-collisions-aux-passages-a-niveau-enfrance.html

SNCF Réseau (2015). 8ème Journée Nationale de Sécurité Routière aux Passages à Niveau [8th National Conference of Road Safety at Level Crossings]. From http://www.sncf-reseau.fr/fr/dossier-de-presse-8eme-journee-nationale-de-securiteroutiere-aux-passages-a-niveau

SNCF (2015). Research on the material of level crossing in 2014, France.

SNCF Réseau (2010). Statistical analysis of accidents at LXs, France.

Stanton, N.A. \& Walker, G.H. (2011). Exploring the psychological factors involved in the Ladbroke Grove rail accident. Accident Analysis \& Prevention, 43(3), 1117-1127.

Stefanova, T., Burkhardt, J.-M., Filtness, A., Wullems, C., Rakotonirainy, A. \& Delhomme, P. (2015). Systems-based approach to investigate unsafe pedestrian behaviour at level crossings. Accident Analysis \& Prevention, 81(0), 167-186.

Tey, L.S., Ferreira, L. \& Wallace, A. (2011). Measuring driver responses at railway level crossings. Accident Analysis \& Prevention, 43(6), 2134-2141.

Weber, P., Medina-Oliva, G., Simon, C. \& Iung, B. (2012). Overview on Bayesian networks applications for dependability, risk analysis and maintenance areas. Engineering Applications of Artificial Intelligence, 25(4), 671-682.

Wigglesworth, E.C. (2001). A human factors commentary on innovations at railroad-highway grade crossings in Australia. Journal of Safety Research, 32(3), 309-321.

Wilson, J.R. (2014). Fundamentals of systems ergonomics/human factors. Applied Ergonomics, 45, 5-13.

Woods, M.D., Slovak, R. \& Schnieder, E. (2008). Safer European Level Crossing Appraisal and Technology: D4- Report on Cost Benefit Analysis methods for level crossings. Rail Safety and Standards Board (RSSB), SELCAT-WP1-W02.

Yehezkel, R. \& Lerner B. (2009). Bayesian network structure learning by recursive autonomy identification. Journal of Machine Learning Research, 10, 1527-1570. 